\begin{tabular}{|lll|}
\hline Diterima & $:$ & 21 April 2020 \\
Direvisi & $:$ & 15 Mei 2020 \\
Disetujui & $:$ & 26 Juni 2020 \\
Diterbitkan & $:$ & 27 Juni 2020 \\
\hline
\end{tabular}

\title{
PENINGKATAN KETERAMPILAN MOTORIK KASAR ANAK USIA DINI MELALUI ANIMAL FUN
}

\author{
Ruruh Ayu Murti Anandya R. ${ }^{1}$, Ruli Hafidah ${ }^{2}$ \& Novita Eka Nurjanah ${ }^{3}$ \\ email: ruruhayu97@gmail.com¹, ruli_hafidah@yahoo.com², \\ novitapaud2@gmail.com ${ }^{3}$ \\ Program Studi Pendidikan Guru PAUD \\ Universitas Sebelas Maret Surakarta
}

Jalan Ir. Sutami No.36 A, Pucangsawit, Jebres, Kota Surakarta, Jawa Tengah 57126

\begin{abstract}
Abstrak: Anak dengan kesulitan motorik kasar seperti melompat, melempar bola, dan menendang bola cenderung terlihat tidak percaya diri, tidak bersemangat, dan sulit mengikuti aktivitas pembelajaran. Keterampilan motorik kasar yang kurang optimal dapat mengganggu aktivitas pembelajaran anak dalam bermain. Perlunya solusi kegiatan yang inovatif dan menyenangkan dalam aktivitas keterampilan motorik sangatlah penting, agar anak berkembang optimal. Penelitian ini bertujuan meningkatkan keterampilan motorik kasar pada anak dengan animal fun. Animal fun adalah kegiatan menirukan gerakan binatang untuk perkembangan motorik dan sosial emosional anak usia pra sekolah. Ini merupakan penelitian tindakan kelas (PTK) model Kemmis \& McTaggart. Teknik pengumpulan data dalam penelitian ini menggunaan unjuk kerja, observasi, wawancara, serta dokumentasi. Teknik uji validitas datanya yaitu triangulasi sumber serta triangulasi teknik. Subjek penelitian meliputi anak kelompok A1 berusia 4-5 tahun berjumlah 18 anak di TK Nurani Patriot Kecamatan Jebres Surakarta tahun ajaran 2018/2019. Hasil penelitian ini menampilkan bahwa keterampilan motorik kasar pada kelompok anak A1 terdapat peningkatan saat pra tindakan sebesar $33,4 \%$, siklus I sebesar $50 \%$, serta siklus II sebesar $83,3 \%$. Uraian tersebut membuktikan bahwa animal fun berhasil meningkatkan keterampilan motorik kasar kelompok anak usia 4-5 tahun di TK Nurani Patriot Kecamatan Jebres tahun ajaran 2018/2019. Hasil inilah yang diharapkan menjadi informasi penting bagi guru dan calon pendidik dalam melakukan evaluasi dan inovasi guna mencari solusi yang tepat dalam mengoptimalkan perkembangan anak.
\end{abstract}

Kata-kata Kunci: anak usia dini, animal fun, keterampilan motorik kasar

\section{THE IMPROVEMENT OF GROSS MOTOR SKILLS IN EARLY CHILDHOOD THROUGH THE ANIMAL FUN}

\begin{abstract}
Children who face difficulties in performing gross motor skills such as jumping, throwing ball, and kicking ball seemed to be insecured, not excited and hard to follow learning activities. Poorly developed gross motor skill can interfere with children's learning activities to play. In order to develop children's gross motor skills optimally, innovative and fun activities are needed. This study aims to improve the gross motor skill through the animal fun activities. The animal fun is the activity of mimicking animal movements so that motor and social emotional skills in preschoolers will be improving. This study is a classroom action research (CAR) with Kemmis \& McTaggart models. The data collection techniques used in this research were performance, observation, interviews, and documentation. The data validity techniques were done through source and technical triangulation. The subjects of this study were eighteen children aged 4 to 5 in an A1 kindergarten class in TK Nurani Patriot Kecamatan Jebres Surakarta in 2018/2019
\end{abstract}


Peningkatan Keterampilan Motorik...

academic year. The results of this study show that improvement in gross motor skill of the A1 group was happening at the pre, first and second cycle, with about $33,4 \%, 50 \%$ and $83,3 \%$ respectively. It proves that the animal fun activity was able to make children mimicking its movements so that increase the gross motor skill of the A1 group in TK Nurani Patriot Kecamatan Jebres in 2018/2019 academic year. The results are expected to be an important information for teachers and educator candidates in evaluating and innovating solutions for optimal children gross motor skills development.

Keywords: animal fun, early childhood, gross motor skill

\section{PENDAHULUAN}

Pendidikan merupakan kebutuhan yang harus dipenuhi untuk membekali diri agar berkembang maksimal. PAUD merupakan upaya pembinaan melalui pemberian rangsangan pendidikan untuk anak dalam membantu pertumbuhan dan perkembangannya. Perkembangan motorik salah satu aspek penting yang ditegaskan dalam tujuan pendidikan anak usia dini (Permendikbud, 2014). Pengembangan keterampilan fisik motorik sangat perlu karena pada usia dini merupakan usia emas (golden age) dimana anak memiliki keingintahuan yang tinggi. Anak mulai mengeksplor lingkungan melalui panca indra dan bergerak aktif, sehingga peka akan stimulasi di sekitarnya. Oleh sebab itu, diperlukan aktivitas fisik pada anak agar dapat terstimulasi optimal karena perkembangan motorik kasar anak usia dini sangat berguna bagi kehidupan anak dimasa mendatang (Beaty, 2014).

Keterampilan fisik motorik dibagi menjadi dua yakni motorik halus dan motorik kasar. Keterampilan motorik kasar adalah keterampilan dasar yang digunakan untuk bergerak dan dasar bagi pengembangan keterampilan yang lebih kompleks (Liu, 2014). Bergerak sebagai dasar aktivitas fisik anak untuk mengeksplorasi lingkungannya. Aktivitas fisik tersebut melibatkan tangan, kaki, dan seluruh tubuh anak dalam mengoptimalkan keterampilan motorik kasarnya dengan menggunakan otot - otot besar melompat, berlari, menangkap bola, melempar bola, menendang bola dan lain sebagainya. Aktivitas fisik tersebut dilakukan untuk pemenuhan keingintahuannya terhadap lingkungan di sekitarnya seperti aktivitas kemandirian, aktivitas bermain, dan kegiatan - kegiatan bermain lainnya dalam pembelajaran di taman kanakkanak.

Peraturan Menteri Pendidikan dan Kebudayaan Republik Indonesia Nomor 137 Tahun 2014 tentang Standar Nasional PAUD yang memuat tingkat pencapaian perkembangan pada motorik kasar anak usia 4 - 5 tahun yakni 1) menirukan gerakan binatang, pohon tertiup angin, dst; 2) melakukan gerak bergelayutan (menggantung); 3) melakukan gerakan lompat, loncat, serta berlari secara terkoordinasi; 4) melempar sesuatu secara terarah; 5) menangkap sesuatu secara tepat; 6) melakukan gerak antisipasi; 7) menendang sesuatu secara terarah; dan 8) memanfaatkan alat permainan luar kelas. Menurut Beaty (2013) keterampilan motorik kasar anak usia 4-5 tahun yakni 1) berjalan dengan langkah selang seling; 2) berlari dengan kecepatan arah terkontrol; 3) melompat dengan 2 kaki bersama; 4) meloncat dengan satu kaki; 5) mendaki, menuruni dan merayapi peralatan; 6) melempar, menangkap, dan menendang bola; 7) mengendarai sepeda; dan 8) melakukan gerakan kreatif. Hal ini sejalan dengan pendapat Sun, dkk. (2010) yang menyatakan bahwa keterampilan motorik kasar pada anak sebagai berikut: 1) berlari; 2) melompat jauh; 3) berlari zig zag; 4) melompat dari sisi ke sisi; 5) melemparkan bola; 6) menangkap bola; dan 7) menendang bola.

Berdasarkan pendapat ahli di atas, peneliti menggunakan aspek keterampilan motorik kasar anak usia dini sesuai dengan Peraturan Menteri Pendidikan dan Kebudayaan Republik Indonesia Nomor 137 Tahun 2014 tentang Standar Nasional PAUD yang memuat tingkat pencapaian perkembangan pada motorik kasar anak yaitu: 1) menirukan gerak binatang dengan sesuai; 2) melakukan gerakan melompat secara terkoordinasi; 3) melempar sesuatu secara terarah; dan 4) menendang sesuatu secara terarah. Aspek tersebut diambil berdasarkan observasi peneliti mengenai tingkat pencapaian perkembangan motorik kasar anak usia 4-5 tahun, ditemukan bahwa terdapat masalah di lapangan dalam perkembangan motorik kasar anak yaitu anak belum mampu melakukan gerakan dari keterampilan motorik kasar diantaranya menirukan beberapa gerak binatang yang mencakup melompat secara terkoordinasi, menendang bola secara terarah, dan melempar bola secara terarah.

Terlihat bahwa keterampilan motorik kasar kelompok A1 di TK Negeri Pembina Kecamatan Jebres yakni 1) melempar bola dengan arah terkontrol 
terdapat 11 anak (62\%) anak belum berkembang; 2 ) menendang bola dengan arah ke depan terdapat 11 anak (62\%) anak belum berkembang; 3) melompat sejauh 4-6 lompatan dengan bertumpu pada 2 kaki terdapat 10 anak (56\%) anak belum berkembang; 4) menirukan gerakan binatang sesuai instruksi, terdapat 14 anak (78\%) belum berkembang. Hal ini didukung dengan wawancara guru yang menyatakan bahwa pengembangan motorik kasar anak kelompok A1 memang belum sepenuhnya optimal dikarenakan beberapa faktor.

Menurut Rahyubi (2012) faktor tersebut diantaranya: 1) kondisi dari tubuh/fisik; dan 2) motivasi yang kuat. Salah satu cara subjektif untuk mengetahui kondisi fisik anak dengan melihat keaktifan beraktivitasnya cukup baik, lincah, dan tidak ada gangguan kesehatan. Faktanya dua anak belum tuntas dalam keterampilan motor kasar ini. Kondisinya kesehatannya lemah, sehingga mudah sakit dan sering tidak masuk sekolah. Faktor lain adalah motivasi anak. Setiap berangkat sekolah selalu menangis, sehingga orang tua harus menunggui anaknya di depan gerbang dan anak baru berhenti menangis dan diam. Kemudian belum mencoba kegiatan anak sudah menyatakan ketidakmampuannya, sehingga kurang optimal dalam melakukan kegiatan.

Wiyani (2014) menjelaskan beberapa faktor yang mempengaruhii perkembangan keterampilan motorik kasar anak seperti 1) faktor makanan dan 2) faktor pemberian stimulus. Pada faktor makanan, terlihat fakta di lapangan masih ada beberapa anak yang sering sakit dan terlihat lesu disebabkan anak tersebut membawa bekal yang kurang sehat seperti snack yang mengandung $M S G$ dan mie goreng instan. Untuk faktor pemberian stimulasi pembelajaran motorik kasar anak belum optimal dan terlihat cepat bosan dan kurangnya partisipasi anak disadari guru bahwa dibutuhkan kegiatan yang lebih bervariasi dan menyenangkan, sehingga dapat menarik perhatian dan ketertarikan anak untuk berkegiatan dalam fisik motorik.

Pentingnya keterampilan motorik kasar dioptimalkan karena memiliki peran penting dalam perkembangan anak. Selain itu beberapa penelitian mengemukakan bahwa hubungan antara perkembangan motorik kasar dengan aspek lain. Lopes, Santos, dan Pereira (2013) melalui hasil penelitiannya menyatakan keterampilan motorik yang rendah memiliki kemungkinan tinggi terhadap prestasi akademik yang rendah. Hal tersebut sejalan dengan Galdi, Anna, Patena dan Gomez (2015) melalui penelitiannya yang menyatakan hubungan motorik kasar dan kognitif anak, aktivitas gerak, dan latihan motorik kasar berkontribusi pada kognitif anak.

Penelitian lain menjabarkan jika anak merasa yakin pada keterampilan motorik kasarnya, mereka lebih terlibat kegiatan pada fisik dengan baik dibanding anak yang kurang yakin terhadap keterampilan diri (Hay, Hawes dan Fraught, 2004; Mandich, Polatajko dan Rodger, 2003). Penelitian lain menjelaskan dampak dari kesulitan motorik di masa dewasa, (Tal-Saban, Ornoy \& Parush. 2014) menyoroti perlu mengatasi tingkat partisipasi fisik anak dengan masalah gerak untuk keterampilan motorik kasar mengingat dampak buruk dari kurangnya partisipasi kegiatan fisik pada kualitas hidup dan risiko kesehatan seperti obesitas dan kardiovaskular (Rivilis, dkk. 2011). Pengembangan aspek sosial anak dapat dilakukan dengan memberi kesempatan mereka berinteraksi dalam situasi bermain antar anak. Schoemaker dan Kalverboer (1994) menjabarkan hubungan antara kesulitan motorik dan masalah sosial afektif pada anak. Tampaknya, di masa Taman kanak-kanak menargetkan pengembangan keterampilan motorik kasar agar optimal sangatlah penting guna menjadi pijakan untuk mempersiapkannya terhadap berbagai perkembangan lain.

Berdasarkan permasalahan dan kesadaran pentingnya stimulasi keterampilan motorik kasar anak dengan pembelajaran inovatif dan menyenangkan, salah satu kegiatan fisk motorik bagi anak usia dini adalah animal fun. Animal fun adalah kegiatan untuk perkembangan motorik dan sosial emosional anak usia pra sekolah yang dirancang oleh tim peneliti multidisiplin dan praktisi kesehatan Australia (Piek, dkk. 2010; De Oliveira, dkk. 2018). Kegiatan ini dilakukan dengan meniru gerak binatang di lingkungan menyenangkan untuk meningkatkan perkembangan motorik kasar, motorik halus dan sosial yang sudah di klasifikasikan dalam modul (Piek, dkk. 2010; 2013).

Kegiatan ini menarik bagi anak karena dengan anak menirukan gerakan binatang, mereka dapat berfokus pada pengembangan motorik kasar dan motorik halusnya serta sosial/emosional mereka dengan lingkungan kegiatan yang menyenangkan dan menarik. Untuk keterampilan motorik kasar dirancang keseimbangan statis dan dinamis, meningkatkan kekuatan otot tungkai bawah, dan mengembangkan minat pada aktivitas lokomotor seperti berlari, melompat dan meloncat, teknik melempar, menangkap, menendang, dan gerak lebih kompleks dengan menggabungkan gerakan bersama.

Kegiatan ini melibatkan semua anak secara kreatif (De Oliveira, dkk. 2018). Kegiatannya berprinsip 
dalam pengembangan keterampilan motorik anak. Chambers \& Sugden mengutarakan bahwa anak perlu merasa kompeten dan percaya diri dalam melakukan kegiatan. Penyampaian guru mengenai kegiatan animal fun dituntut kreatif dengan menirukan gerakan binatang sesuai masalah anak. Gerakan binatang dipilih sesuai dengan keterampilan yang akan ditingkatkan seperti melompat terkoordinasi dengan menirukan gerak binatang kangguru sedang melompat, melempar bola dengan menirukan gerakan monyet sedang melempar, dan menendang bola dengan menirukan gerak binatang burung kasuari sedang menendang. Teknik penyampaian guru penting namun diutamakan anak menikmati yang dilakukan sehingga mereka akan terus berlatih dan meningkatkan keterampilan motoriknya (Piek, dkk. 2010). Gerak yang anak lakukan harus bermakna dimana mereka suka meniru, dengan meniru gerak binatang. Mereka melekatkan makna pada tugas keterampilan motorik kasar dengan senang (Piek, dkk. 2010)

Keterampilan pada motorik kasar merupakan gerak otot-otot besar, diantaranya gerakkan lengan serta berjalan (Santrock, 2011). Pengunaan otot besar merupakan dasar keterampilan motorik kasar. Demikian pentingnya untuk dipantau perkembangan anak dalam setiap aktivitas. Pendapat lain dikemukakan (Beaty, 2013) keterampilan motorik kasar masuk dalam aktivitas motorik diantaranya seperti gerakan otot-otot besar, kekuatan fisik keseimbangan, melibatkan tangan, kaki, juga seluruh tubuh. Gerak motorik mengandalkan kematangan sesuai tahapan perkembangan. Hal senada diungkapkan oleh Liu (2014). la menjabarkan keterampilan motorik kasar adalah keterampilan dasar gerak dan pengembangan keterampilan lebih kompleks.

Keterampilan motorik kasar mencakup berbagai aspek perkembangan seperti yang dipaparkan Zawi, Choon Lian dan Abdullah (2014) terdiri dari 1) gerak lokomotor yaitu gerak berpindah; 2) gerak stasioner, yaitu gerak mempertahankan keseimbangan dan 3) gerak manipulatif yaitu gerak memanipulasi benda. Gerak di indikator keterampilan motorik kasar penelitian ini diadaptasi dari berbagai pendapat ahli yang disesuaikan dengan Peraturan Menteri Pendidikan Kebudayaan Republik Indonesia Nomor 137 Tahun 2014 tentang Standar Nasional PAUD . Indikator tersebut diambil dengan alasan sesuai permasalahan di lapangan dengan kegiatan animal fun.

Kegiatan meniru gerakan binatang dengan cara menyenangkan, animal fun (Piek, dkk. 2010) bertujuan mengembangkan keterampilan motorik dan sosial, serta meningkatkan kepercayaan diri anak terhadap keterampilan motorik (Piek, dkk. 2013). Tujuan pengembangan dalam keterampilan motorik kasar, bersumber pendapat Laren Sue Mc. (1968) dalam buku "Animal Fun" dimana kegiatan tersebut dikelompokkan dalam 9 modul (Piek, dkk. 2013). Setiap modul menguraikan berbagai gerakan binatang sesuai aspek yang tercantum, sehingga peneliti dapat memilih gerakan binatang yang akan digunakan guna meningkatkan indikator yang kurang optimal.

Untuk pengembangan motorik kasar terdapat pada modul 1-5, yaitu modul 1 Body Management (keseimbangan statis dan dinamis); modul 2 Lokomotor (berjalan, melompat, melompat, melompat); modul 3: control object (melempar, menangkap, menendang); modul 4: body sequecing (batang tubuh dan tungkai bawah); modul 5: body manajement and kinaesthetic (koordinasi mata dan gerak tangan serta tubuh). Pada tiga modul berikutnya menjabarkan pengembangan motorik halus yakni modul 6 perencanaan motorik halus; modul 7 control object (keterampilan pragunting/gunting, penggunaan kuas cat, keterampilan menggambar/pra menulis); modul 8 hand skill (kekuatan jari individu, kekuatan genggaman, genggaman menjepit). Untuk modul terakhir mengembangkan sosial emosional yaitu modul 9 social emosional development (tertawa, mengidentifikasi dan memberi label perasaan, pernapasan dalam mengelola perasaan, relaksasi).

Karakteristik Animal Fun meningkatkan keterampilan motorik kasar, peneliti menggunakan gerakan binatang yang bersumber pendapat Laren Sue Mc. (1968) dalam buku “Animal Fun". Pada modul 2 dan 3 yakni baby monkey untuk indikator melempar bola dengan arah terkontrol, cassowary kicking untuk indikator menendang bola dengan arah kedepan, dan kangaroo jumps untuk indikator melompat jauh secara terkoordinasi. Binatang ini dipilih karena sesuai masalah di lapangan untuk dioptimalkan kegiatan yang menyenangkan. Kelebihan animal fun menurut Laren Sue Mc. (1968) yakni 1) gerak mudah diikuti dan diimplementasi; 2) menyenangkan bagi guru dan anak saat melakukan; 3) fleksibel dalam pembelajaran; 4) kegiatan dapat dilakukan setiap hari dengan kreatifitas guru sehingga tercipta kelas bahagia, responsif, dan produktif; 5) berdampak positif untuk menarik perhatian anak karena gerak binatang sebagai objek yang diikuti geraknya.

Melihat uraian di atas maka peneliti tertarik lakukan penelitian pada anak usia 4-5 tahun, berupaya meningkatkan keterampilan motorik kasar melalui "animal fun". Animal Fun sebagai kegiatan 
meningkatkan keterampilan motorik kasar anak. Hal ini sesuai hasil penelitian (Piek, dkk. 2010; 2013 dan De Oliveira, dkk. 2018) bahwa animal fun dapat digunakan sebagai kegiatan dalam mengoptimalkan keterampilan motorik kasar anak usia dini. Berdasarkan latar belakang yang diuraikan dapat dirumuskan permasalahan yakni apakah "animal fun" dapat meningkatkan keterampilan motorik kasar anak kelompok A1 TK Negeri Pembina Kecamatan Jebres tahun ajaran 2018/2019? dan bagaimana penerapan "animal fun" untuk meningkatkan keterampilan motorik kasar anak kelompok A1 TK Negeri Pembina Kecamatan Jebres tahun ajaran 2018/2019?

Oleh karena rumusan masalah yang sudah terurai, tujuan di dalam penelitian ini yakni mengetahui keterampilan motorik kasar pada anak kelompok A1 TK Negeri Pembina Kecamatan Jebres melalui "animal fun" dan mendeskripsikan penerapan "animal fun" dalam meningkatkan keterampilan motorik kasar kelompok anak A1 TK Negeri Pembina Kecamatan Jebres tahun ajaran 2018/2019. Penelitian ini diharapkan dapat memberikan manfaat yakni memberi inovasi dan kreativitas kegiatan pembelajaran menyenangkan serta menarik minat anak dalam upaya mengoptimalkan perkembangannya terutama keterampilan motorik kasar dengan penerapan "animal fun" sehingga anak mendapat stimulasi, motivasi dan pengalaman dengan "animal fun".

\section{METODE PENELITIAN}

Penelitian ini adalah penelitian tindakan kelas (PTK) dengan prosedur penelitian model Kemmis \& McTaggart (Tampubolon, 2014) terdiri dari spiral tahapan yakni perencanaan, tindakan dan pengamatan, kemudian refleksi. Subjek penelitiannya yakni anak kelompok A1 usia 4-5 tahun berjumlah 18 anak di TK Negeri Pembina Kecamatan Jebres Surakarta dalam tahun ajaran 2018/2019. Alasan memilih subjek tersebut karena anak belum optimal dalam keterampilan motorik kasarnya.

Penelitian ini memperoleh dari data kuantitatif dari hasil proses belajar keterampilan motorik kasar anak beserta rubrik penilaian dan data kualitatif dari informasi kondisi anak terkait keterampilan motorik kasar seperti nama anak, foto, hasil wawancara guru, serta catatan observasi. Sumber data penelitian ini meliputi sumber data primer (anak dan guru kelompok A1 dan sumber data sekunder (berasal dari foto video anak ketika proses pembelajaran animal fun untuk peningkatan keterampilan motorik kasar berlangsung).

Teknik pengumpulan data menggunakan unjuk kerja, observasi, wawancara, serta dokumentasi. Teknik uji validitas data menggunakan triangulasi sumber dan triangulasi teknik. Teknik analisis data penelitian ini yakni data kuantitatif dianalisis menggunakan teknik analisis data komparatif (dengan statistik deskriptif disajikan dalam bentuk grafik dan tabel) dan analisis data kualitatif dengan 4 alur yang dikemukakan Miles \& Huberman (1992) yaitu pengumpulan data, reduksi data, penyajian data, penarikan kesimpulan, atau verifikasi.

Indikator penelitian ini diadaptasi dari berbagai pendapat ahli dan telah sesuai dengan Peraturan Menteri Pendidikan dan Kebudayaan Republik
Indonesia Nomor 137 Tahun 2014 tentang Standar Nasional PAUD mengenai keterampilan fisik motorik kasar dari Beaty (2013), Santrock, (2011), dan Sun, $d k k ;$ (2010) sebagai berikut :

Tabel 1.

Indikator Keterampilan Motorik Kasar

\begin{tabular}{cll}
\hline No & \multicolumn{1}{c}{$\begin{array}{c}\text { Aspek } \\
\text { Penilaian Indikator }\end{array}$} & \multicolumn{1}{c}{ Kegiatan } \\
\hline 1 & $\begin{array}{l}\text { Melempar bola dengan } \\
\text { arah terkontrol }\end{array}$ & Baby monkey \\
2 & $\begin{array}{l}\text { Menendang bola dengan } \\
\text { arah ke depan, }\end{array}$ & $\begin{array}{l}\text { Cassowary } \\
\text { kicking }\end{array}$ \\
3 & $\begin{array}{l}\text { Melompat 4-6 langkah } \\
\text { lompatan bertumpu } 2 \\
\text { kaki, } \\
4\end{array}$ & Kangaroo jumps \\
binatang sesuai instruksi. & $\begin{array}{l}\text { Kaby monkey, } \\
\text { cassowary } \\
\text { kicking, dan } \\
\text { kangaroo jump }\end{array}$ \\
\hline
\end{tabular}

Setiap kegiatan animal fun memuat langkah persiapan (mempersiapkan segala alat bahan yang digunakan dalam kegiatan pembelajaran), posisi awal (melakukan pemanasan, menata tata letak anak sebelum kegiatan, mengenalan animal fun serta memberi penjelasan mengenai kegiatan yang akan dilakukan), gerakan inti (memberi contoh dan mempraktekan gerakan kegiatan yang dilakukan), tambahan (memberi kesempatan anak mencoba kegiatan dan melakukannya berulang) dan poin kritis (peneliti melakukan pengamatan pada anak mengenai indikator keterampilan motorik kasar yang dilakukan anak dan menilai serta merefleksi). Pelaksanaan kegiatan disesuaikan antara binatang yang dipilih dalam modul dengan indikator seperti tabel 1 .

Hipotesis penelitian: "Dengan menggunakan 
animal fun diperoleh hasil keterampilan motorik kasar kelompok anak A1 di TK Negeri Pembina Kecamatan Jebres dapat meningkat". Meningkatnya keterampilan motorik kasar anak dapat diketahui dari setiap indikator yang termuat pada tabel di atas pada anak dari setiap kegiatan animal fun yang sudah dilakukan (kegiatan baby monkey, cassowary kicking, dan kangaroo jump) berupa hasil catatan observasi, hasil penilaian, hasil catatan dokumentasi dan catatan wawancara kemudian diambil kesimpulan dampak kemanjuran hasil dari kegiatan animal fun terhadap keterampilan motorik kasar anak berusia 4 sampai 5 tahun.

\section{HASIL DAN PEMBAHASAN}

\section{Hasil}

Keterampilan motorik kasar anak kelompok A1 TK Negeri Pembina Kecamatan Jebres dari hasil pratindakan, siklus I, hingga siklus II ada peningkatan. Indikator penilaian yaitu melempar bola dengan arah terkontrol; menendang bola arah dengan arah kedepan; melompat jauh 4-6 lompatan bertumpu pada 2 kaki; menirukan gerak binatang sesuai intruksi meningkat. Berikut tabel hasil pratindakan:

Tabel 2.

Persentase Ketuntasan Klasikal Keterampilan Motorik Kasar Pratindakan

\begin{tabular}{ccc}
\hline $\begin{array}{c}\text { Kriteria } \\
\text { Ketuntasan }\end{array}$ & $\begin{array}{c}(\mathbf{f}) \\
\text { Frekuensi }\end{array}$ & $\begin{array}{c}(\mathbf{\%}) \\
\text { Persentase }\end{array}$ \\
\hline Tuntas & 6 & $33,33 \%$ \\
Belum Tuntas & 12 & $66,67 \%$ \\
\hline Jumlah & $\mathbf{1 8}$ & $\mathbf{1 0 0} \%$ \\
\hline
\end{tabular}

Berdasarkan tabel tersebut maka dapat diungkapkan persentase ketuntasan klasikal keterampilan motorik kasar prasiklus anak adalah $33,33 \%$ atau 6 anak tuntas serta $66,67 \%$ atau 12 belum tuntas. Hasil menunjukkan keterampilan motorik kasarnya kelompok anak A1 di TK Negeri Pembina Kecamatan Jebres masih rendah dan perlu ditingkatkan. Setelah terlaksananya siklus I, terlihat ada peningkatan. Berikut beberapa dokumentasi kegiatan animal fun yakni baby monkey untuk melempar bola, cassowary kicking untuk menendang bola, dan kangaroo jumps untuk melompat jauh. ketika penerapan animal fun dilaksanakan:

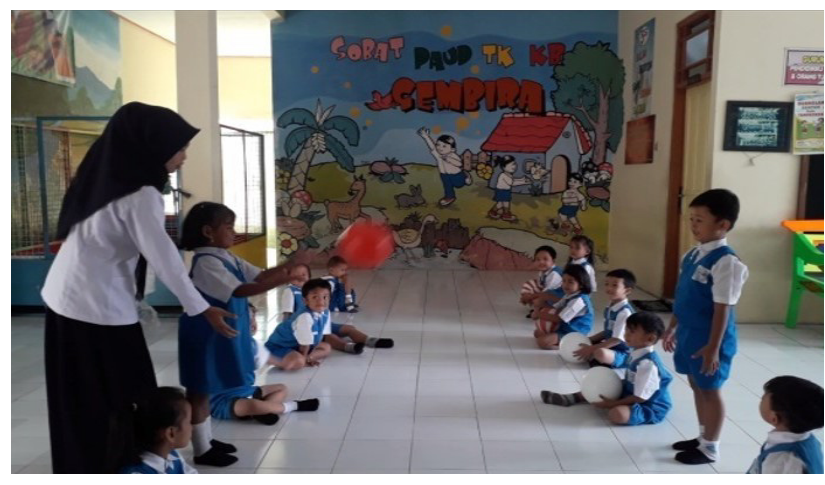

Gambar 1. Penerapan animal fun dengan kegiatan baby monkey

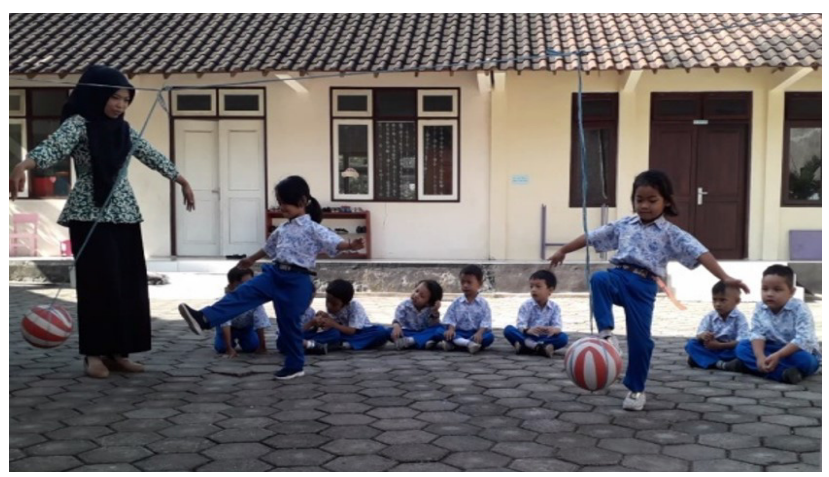

Gambar 2. Penerapan animal fun dengan kegiatan cassowary kicking

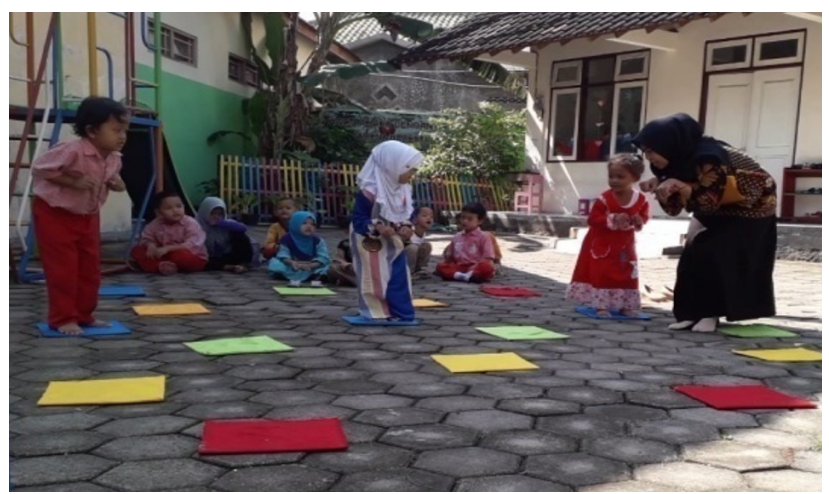

Gambar 3. Penerapan animal fun dengan kegiatan kangaroo jump

Terbukti tabel persentase ketuntasan klasikalnya keterampilan motorik kasar siklus I berikut:

Tabel 3.

Persentase Ketuntasan Klasikal Keterampilan Motorik Kasar Siklus I

\begin{tabular}{lcc}
\hline $\begin{array}{c}\text { Kriteria } \\
\text { Ketuntasan }\end{array}$ & $\begin{array}{c}\text { (f) } \\
\text { Frekuensi }\end{array}$ & $\begin{array}{c}(\mathbf{\%}) \\
\text { Persentase }\end{array}$ \\
\hline Tuntas & 9 & $50 \%$ \\
Belum Tuntas & 9 & $50 \%$ \\
\hline Jumlah & $\mathbf{1 8}$ & $\mathbf{1 0 0 \%}$ \\
\hline
\end{tabular}

Berdasarkan tabel maka diketahui persentase ketuntasan klasikal keterampilan motorik kasar anak siklus I adalah $50 \%$ atau 9 anak mendapat nilai tuntas dan $50 \%$ atau 9 anak belum tuntas. Apabila dibandingkan dengan pratindakan maka anak mengalami peningkatan sebanyak $16,67 \%$. Persentase ketuntasan klasikal siklus I belum memenuhi target 
pencapaian yaitu $75 \%$ yang ditetapkan, maka dilanjut tindakan selanjutnya dengan memperhatikan refleksi sebelumnya.

Siklus II mengalami peningkatan keterampilan motorik kasar di kelompok anak A1 TK Negeri Pembina Jebres. Berikut persentasenya ketuntasan klasikal siklus II pada keterampilan motorik kasarnya:

Tabel 4.

Persentase Ketuntasan Klasikal Keterampilan Motorik Kasar Siklus II

\begin{tabular}{ccc}
\hline $\begin{array}{c}\text { Kriteria } \\
\text { Ketuntasan }\end{array}$ & $\begin{array}{c}(\mathbf{f}) \\
\text { Frekuensi }\end{array}$ & $\begin{array}{c}(\mathbf{\%}) \\
\text { Persentase }\end{array}$ \\
\hline Tuntas & 15 & $83,33 \%$ \\
Belum Tuntas & 3 & $16,67 \%$ \\
\hline Jumlah & $\mathbf{1 8}$ & $\mathbf{1 0 0 \%}$ \\
\hline
\end{tabular}

Berdasar tabel tersebut maka diketahui hasil tuntas siklus II adalah $83,33 \%$ atau 15 anak mendapat tuntas dan $16,67 \%$ atau 3 anak belum tuntas. Dibandingkan hasil ketuntasan siklus I maka mengalami peningkatan sebesar $33,33 \%$. Persentase ketuntasan klasikal siklus II mencapai $83,33 \%$ tuntas, dimana anak telah memenuhi target pencapaian yang ditetapkan yaitu $75 \%$.

Keterampilan pada motorik kasar anak mengalami peningkatan signifikan, berikut gambar diagram perbandingan hasil unjuk kerja keterampilan motorik kasar anak antar siklus:

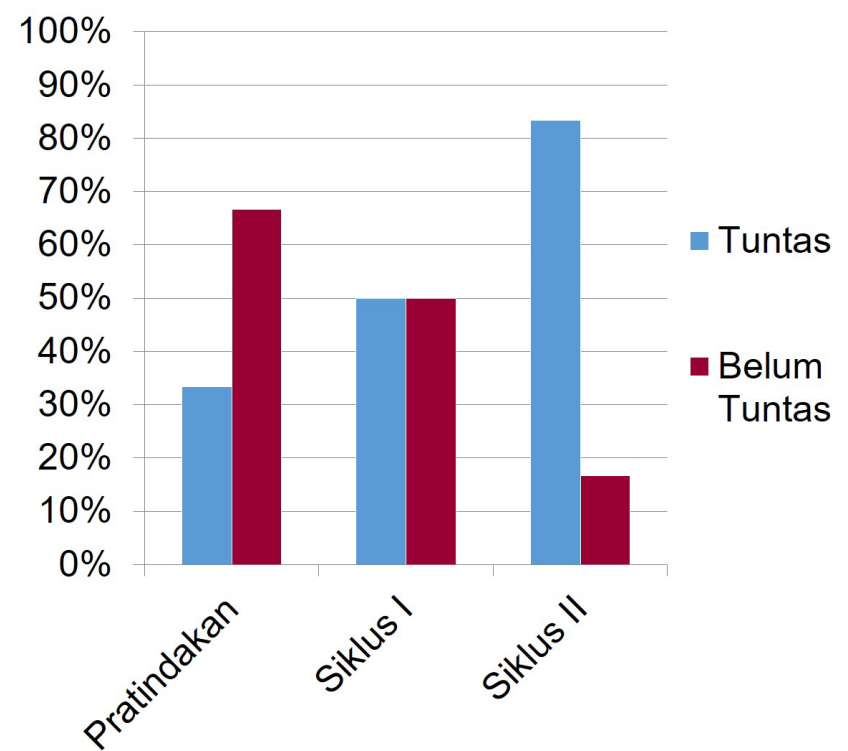

Gambar 4. Grafik Perbandingan Ketuntasan Klasikal antar Siklus

Berdasarkan data tersebut, maka perolehan ketuntasan keterampilan motorik kasar secara klasikal mulai pratindakan, siklus I, serta siklus II bisa dideskripsikan bahwa keterampilan motorik kasar anak saat pratindakan masih kesulitan ketika melakukan indikator yaitu melempar bola dengan arah terkontrol, menendang bola dengan arah ke depan, melompat 4-6 langkah lompatan bertumpu pada 2 kaki, dan menirukan gerakan binatang sesuai instruksi dan terlihat persentase ketuntasan hanya sebesar $33,33 \%$ atau 6 anak memperoleh nilai tuntas. Kondisi ini menunjukan perlunya penerapan kegiatan animal fun untuk meningkatkan keterampilan anak, mengacu pada pendapat Beaty (2013), Santrock, (2011), dan Sun, dkk; (2010) yang disesuaikan dengan Peraturan Menteri Pendidikan dan Kebudayaan Republik Indonesia Nomor 137 Tahun 2014 tentang Standar Nasional PAUD mengenai tingkat pencapaian keterampilan motorik kasar anak usia 4-5 tahun berupa aspek indikator tersebut seharusnya sudah dapat dicapai dengan optimal oleh anak kelompok $\mathrm{A} 1$ yang mana mereka berada dalam direntang usia tersebut.

Penerapan animal fun telah dilaksanakan, dengan hasil keterampilan pada motorik kasarnya anak saat siklus I ada peningkatan sebanyak $16,67 \%$ menjadi $50 \%$ atau 8 anak memperoleh nilai tuntas. Hasil siklus I belum sesuai target peneliti, yang merujuk pada pendapat Aqib, dkk (2014) bahwa penelitian secara klasikal dikatakan berhasil apabila mencapai minimal $75 \%$ dari jumlah anak yaitu 14 anak dari 18 anak mencapai tingkat pencapaian perkembangan minimal. Peningkatan berlanjut pada siklus II dengan peningkatan sebesar $33,33 \%$ menjadi $83,33 \%$ atau 11 anak memperoleh nilai tuntas. Sehingga peningkatan persentase ketuntasan keterampilan motorik kasar anak secara klasikal setelah diterapkan animal fun sebesar $50 \%$. Apabila melihat data tersebut, maka penerapan animal fun telah meningkatkan keterampilan pada motorik kasarnya kelompok anak A1 di TK Negeri Pembina Kecamatan Jebres.

\section{Pembahasan}

Berdasar hasil penelitian yang telah terlaksana oleh peneliti pada anak kelompok A1 TK Negeri Pembina di Kecamatan Jebres tahun ajaran 2018/2019, setelah tindakan penerapan animal fun terdapat peningkatan keterampilan motorik kasar. Hasil peningkatan ini sejalan dengan penelitian sebelumnya, yang mengungkapkan mengenai kemanjuran animal fun dalam meningkatkan keterampilan motorik kasar anak berupa menirukan gerak binatang. (Piek, dkk. 2013) menemukan peningkatan keterampilan pada motorik kasar anak-anak yang ikut kegiatan animal fun.

Pendidikan prasekolah adalah waktu awal yang penting dalam mengembangkan keterampilan dan merupakan tahun pertama sekolah anak sehingga penting dalam perkembangan anak ( $\mathrm{La}$ 
Paro, dkk. 2000). Anak-anak diberi kesempatan belajar dan mempraktikkan keterampilan melalui kegiatan sesuai dengan perkembangannya dan hasil penelitian memberikan bukti bahwa animal fun mampu meningkatkan keterampilan motorik kasar anak dalam gerakan - gerakan, dengan pendekatan menyenangkan. Animal fun (Piek, dkk. 2010) dirancang oleh tim peneliti multidisiplin dan praktisi kesehatan australia meningkatkan keterampilan motorik dan sosial anak 4-6 tahun dengan meniru gerak binatang di lingkungan yang menyenangkan.

Peningkatan terjadi pada setiap indikator. Kegiatan yang dilakukan untuk mengukur setiap indikator yakni kegiatan Baby Monkey pada pertemuan I, Cassowary Kicking pada pertemuan II, dan Kangaroo Jump pada pertemuan III. Berdasarkan hasil wawancara guru kelas A1 TK Negeri Pembina Kecamatan Jebres dan berdasarkan pengamatan peneliti, dari seluruh kegiatan animal fun dapat disimpulkan faktor yang pengaruhi perkembangan keterampilan anak yakni faktor kondisi fisik, motivasi yang kuat dan kepribadian anak terlihat kurang percaya diri dan ragu ketika melakukan kegiatan, faktor makanan dan faktor pemberian stimulus yang dirasa kurang.

Solusi untuk permasalahan terkait anak belum tuntas yakni menggali informasi penyebab dan faktor yang memungkinkan belum tuntasnya keterampilan motorik kasar anak. Penyebabnya kemudian diberi penanganan yang tepat sesuai dengan permasalahan yang ada. Faktor stimulus yang menjadi penyebab belum tuntas anak pada keterampilan motorik kasar, menurut Wiyani (2014) mengungkapkan pemberian stimulus seperti mengajak anak lakukan kegiatan bermain dengan melibatkan gerak fisik dapat mempengaruhi perkembangan motorik anak dimana kegiatan dapat dilakukan rutin dan menyenangkan. Ini sudah dilakukan peneliti dengan menerapkan kegiatan animal fun yang memberikan hasil positif yakni anak mengalami peningkatan. Solusi masalah faktor makan yaitu menurut Wiyani (2014) pemberian nutrisi maupun gizi cukup mampu merangsang pertumbuhan dan perkembangan organ tubuh. Pendapat tersebut dimaksudkan untuk orang tua memberi makanan sehat untuk anak. Bersinergi dengan orang tua untuk memperhatikan faktor gizi yang masuk ke tubuh anak salah satunya makanan dan minuman anak.

Solusi masalah faktor kepribadian berupa tidak percaya diri, terdapat salah satu implikasi reward dilihat dari bentuknya yaitu pemberian senyuman, pandangan, dan tepuk panggung dapat membangun kepercayaan diri dan pengembangan potensi diri. Magdalena (2018) terdapat tiga jenis hadiah atau reward, yaitu berupa barang, pujian, dan perlakuan istimewa. Selain itu, anak kurang optimal dalam keterampilan motorik kasar juga dapat diatasi dengan kolaborasi antara guru dan orang tua memberikan dukungan kepada anak agar anak semangat dan terlibat aktif dalam pembelajaran. Orang tua hendaknya memberi tanggapan yang membangun anak dan memberi perhatian terhadap makanan bekal sehingga memberi efek kesehatan anak. Efek makanan dan dukungan agar anak sehat berdampak dalam mendukung aktifitas anak.

Uraian tersebut sesuai dengan teori yang dikemukakan Widayati dan Widijati (2008) bahwa orang tua seharusnya bersikap proaktif dan tidak reaktif saat memberikan tanggapan terhadap aktivitas yang telah selesai dilakukan anak. Sikap proaktif di sini untuk membangun semangat anak lebih baik lagi saat berkegiatan terutama kegiatan animal fun guna meningkatnya keterampilan pada motorik kasar. Selain meningkatkan keterampilan pada motorik kasar, penerapan animal fun di TK Negeri Pembina Kecamatan Jebres juga telah terbukti meningkatkan sosial dan perilaku (Piek, dkk. 2015) menumbuhkan rasa percaya diri dan keberanian anak. Saat melakukan animal fun, anak percaya bahwa dirinya dapat melakukan kegiatan-kegiatan dalam animal fun yang telah dijelaskan, mereka berani untuk mencoba melakukan gerakan saat kegiatan animal fun.

Temuan lain yang peneliti temukan yaitu anak terlihat antusias dan senang. Anak bersemangat ketika melakukan animal fun bersama peneliti. Anak juga sangat ulet dalam melakukan gerakan menirukan binatang, anak berusaha mencoba terus menerus ketika belum bisa melakukan gerakan animal fun. Sejalan dengan hal tersebut, animal fun (Piek, dkk. 2010) dirancang tim peneliti multidisiplin dan praktisi kesehatan untuk meningkatkan motorik dan sosial anak usia 4-6 tahun dengan meniru gerak binatang dalam lingkungan yang menyenangkan. Salah satu tujuan animal fun yaitu meningkatnya rasa kegembiraan saat berkegiatan dan ketertarikan anak padahal menarik yakni gerak binatang yang mana bagi anak selalu dianggap menarik untuk ditiru, seperti yang terjadi pada anak-anak kelompok A1 TK Negeri Pembina Kecamatan Jebres saat melakukan animal fun dalam lingkungan kegiatan bermain yang menyenangkan. 


\section{PENUTUP}

Simpulan hasil dalam penelitian ini memperlihatkan bahwa terdapat peningkatan keterampilan motorik kasar yakni pada indikator 1) melempar bola dengan arah terkontrol, 2) menendang bola dengan arah ke depan, 3) melompat 4-6 langkah lompatan bertumpu pada 2 kaki, dan 4) menirukan gerak binatang sesuai instruksi. Terbukti hasil persentase ketuntasan menunjukan pada siklus I meningkat $16,67 \%$ menjadi $50 \%$ atau 8 anak memperoleh nilai tuntas. Peningkatan berlanjut siklus II dengan peningkatan $33,33 \%$ menjadi $83,33 \%$ atau 11 anak tuntas.

Kegiatan Animal fun membuat anak senang dan saling menyemangati antar anak saat berkegiatan seperti memberi tepuk tangan, tersenyum dan ceria. Anak juga menjadi lebih percaya diri serta berani dalam melakukan kegiatan baru. Dengan demikian animal fun terbukti tidak hanya meningkatkan keterampilan motorik kasar tetapi juga perkembangan sosial emosional anak.

Penelitian ini menyarankan pada guru TK dan orang tua secara bersama-sama berkontribusi dalam pembelajaran aktivitas fisik terutama motorik kasar. Orang tua dapat mendukung kegiatan anak dengan memberi makanan yang sehat dan memberi perhatian yang dibutuhkan anak. Untuk guru dan calon pendidik dapat memberi inovasi kegiatan yang menarik dan kreatif melalui berbagai pilihan gerak binatang dalam kegiatan animal fun ini agar anak selalu bersemangat dan antusias dalam melakukan kegiatan fisik motorik.

Dengan demikian perkembangan keterampilan motorik kasar anak dapat meningkat optimal. Berbagai pendapat ahli telah menjabarkan bahwa keterampilan motorik berhubungan dengan berbagai perkembangan yang lain seperti sosial, kognitif, dan emosinya. Keterampilan motorik kasar yang optimal membuat tubuh sehat dan membantu perkembangan lain tumbuh optimal.

\section{DAFTAR PUSTAKA}

Aqib Z., dkk. (2014). Penelitian Tindakan Kelas untuk Guru SD, SLB, dan TK. Bandung: Yrama Widya.

Beaty, J. (2013). Observasi Perkembangan Anak Usia Dini. Terj. A. Rakhman. Jakarta: Kencana Prenadamedia Group.

Chambers, M., \& Sugden, D. (2003). Intervention in children with Developmental Coordination Disorder: the role of parents and teachers. British Journal of Educational Psychology 2003, 73:545-561. https://doi. org/10.1348/000709903322591235

De Oliveira, J. A., Rigoli, D., Kane, R., McLaren, S., Goulardins, J. B., Straker, L. M., Dender, A., Rooney, R., \& Piek, J. P. (2019). Does "Animal Fun" improve aiming and catching, and balance skills in young children? Research in Developmental Disabilities, 84 (June), 122-130. DOI: 10.1016/j.ridd.2018.07.004

Galdi, M., D’Anna, C., Pastena, N., \& Paloma, F. G. (2015). Gross-motor Skills for Potential Intelligence Descriptive Study in a Kindergarten. Procedia - Social and Behavioral Sciences, 174, 3797-3804. DOI: 10.1016/j. sbspro.2015.01.1115.

Hay, J. A., Hawes, R., \& Faught, B. E. (2004). Evaluation of a screening instrument for developmental coordination disorder. Journal of Adolescent Health, 34 (4), 308-313. DOI: j.jadohealth.2003.07.004

Hurlock, Elizabeth B. (2013). Perkembangan Anak. Terj. Dr. Med. Meitasari Tjandrasa \& Dra. Muslichah Zarkasih. Jakarta: Erlangga. (Buku asli diterbitkan 1978).

La Paro, K. M., Pianta, R. C., \& Cox, M. J. (2000). Teachers' reported transition practices for children transitioning into kindergarten and first grade. Exceptional Children, 67 (1), 7-20. DOI: 10.1177/001440290006700101

Laren Sue Mc, dkk. (1968). Animal Fun. Wst Australia: Goverment of Westren Australia Mental Health Commission (akses menggunakan akun https:animalfun.com.au)

Liu, T. (2014). Gross Motor Performance by Children with Autism Spectrum Disorder and Typically Developing Children on TGMD-2. Journal of Child and Adolescent Behaviour, 2 (1), 2-4. DOI: 10.4172/jcalb.1000123

Lopes, L., Santos, R., Pereira, B., \& Lopes, V. P. (2013). Associations between gross Motor Coordination and Academic Achievement in elementary school children. Human Movement Science, 32 (1), 9-20. DOI: 10.1016/j.humov.2012.05.005

Magdalena, M. (2018). Melatih Kepercayaan Diri Siswa Dalam Menyatakan Tanggapan Dan Saran Sederhana melalui Penguatan Pujian Pada Pembelajaran Bahasa Indonesia. Jurnal KIBASP 
(Kajian Bahasa, Sastra dan Pengajaran). https:// doi.org/10.31539/kibasp.v1i2.282

Mandich, A. D., Polatajko, H. J., \& Rodger, S. (2003). Rites of passage: Understanding participation of children with developmental coordination disorder. Human Movement Science, 22 (4-5), 583-595. DOI: 10.1016/j.humov.2003.09.011

Miles, M.B \& Huberman, A.M. (1992). Analisa Data Kualitatif (Penerjemah Tjetjep Rohendi R). Jakarta: Universitas Indonesia Press.

Permendikbud Nomor 137 Tahun 2014 Tentang Standar Nasional Pendidikan Anak Usia Dini.

Piek, J. P., Kane, R., Rigoli, D., McLaren, S., Roberts, C. M., Rooney, R., Jensen, L., Dender, A., Packer, T., \& Straker, L. (2015). Does the Animal Fun program improve social-emotional and behavioural outcomes in children aged 4-6 years? Human Movement Science, 43, 155-163. DOI: 10.1016/j.humov.2015.08.004

Piek, J. P., McLaren, S., Kane, R., Jensen, L., Dender, A., Roberts, C., Rooney, R., Packer, T., \& Straker, L. (2013). Does the Animal Fun program improve motor performance in children aged 4-6years? Human Movement Science, 32 (5), 1086-1096. DOI: 10.1016/j.humov.2012.08.004

Piek, J. P., Straker, L. M., Jensen, L., Dender, A., Barrett, N. C., McLaren, S., Roberts, C., Reid, C., Rooney, R., Packer, T., Bradbury, G., \& Elsley, S. (2010). Rationale, design and methods for a randomised and controlled trial to evaluate "Animal Fun" - a program designed to enhance physical and mental health in young children. BMC Pediatrics, 10 (1), 78. DOI: 10.1186/14712431-10-78

Rahyubi Heri. (2012). Teori- Teori Belajar dan aplikasi Pembelajaran Motorik. Jawa Barat : Nusa Media

Rivilis, I., Hay, J., Cairney, J., Klentrou, P., Liu, J., \& Faught, B. E. (2011). Physical activity and fitness in children with developmental coordination disorder: A systematic review. Research in Developmental Disabilities, 32 (3), 894-910.
DOI: 10.1016/j.ridd.2011.01.017

Santrock John W. (2011). Masa Perkembangan Anak. Jakarta: Salemba Humanika

Schoemaker, M. M., \& Kalverboer, A. F. (1994). Social and affective problems of children who are clumsy: How early do they begin? Adapted Physical Activity Quarterly, 11 (2), 130-140. DOI: 10.1123/apaq.11.2.130

Skinner, R. A., \& Piek, J. P. (2001). Psychosocial implications of poor motor coordination in children and adolescents. Human Movement Science, 20 (1), 73-94.

Sun, S. H., Zhu, Y. C., Shih, C. L., Lin, C. H., \& Wu, S. K. (2010). Development and initial validation of the preschooler gross motor quality scale. Research in Developmental Disabilities, 31 (6), 1187-1196. DOI: 10.1016/j.ridd.2010.08.002

Tal-Saban, M., Ornoy, A., \& Parush, S. (2014). Young adults with developmental coordination disorder: A longitudinal study. American Journal of Occupational Therapy, 68 (3), 307-316. DOI: 10.5014/ajot.2014.00956

Tampubolon, S.M. (2014). Penelitian tindakan kelas: untuk pengembangan profesi pendidik dan keilmuan. Penerbit erlangga

Widayati, S. \& Widijati, U. (2008). Mengoptimalkan 9 Zona Kecerdasan Majemuk Anak. Jogjakarta: Luna Publisher.

Wiyani, Novan Ardy. (2014). Psikologi Perkembangan Anak Usia Dini Panduan bagi Orang Tua dan Pendidik PAUD dalam Memahami serta Mendidik Anak Usia Dini. Yogyakarta: Gava Media.

Zawi, K., Lian, D. K. C., \& Abdullah, R. T. (2014). Gross motor development of Malaysian hearing impaired male preand early school children. (2014). Young adults with developmental coordination disorder: A longitudinal study. American Journal of Occupational Therapy, 68 (3), 307-316. DOI: 10.5014/ajot.2014.00956 